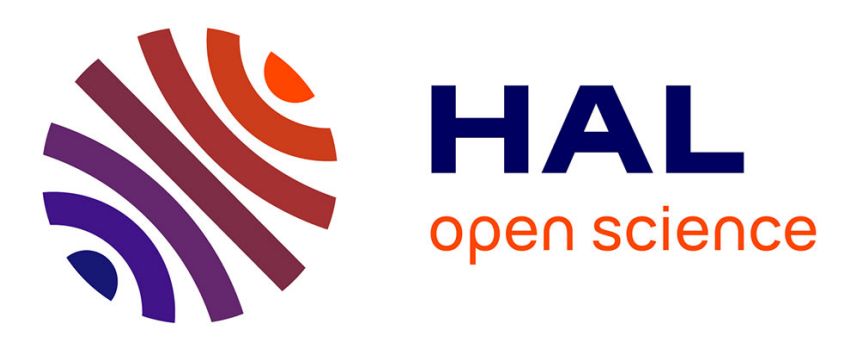

\title{
Effects of Strain Path Changes on the Kinematics and the Intrinsic Dissipation Accompanying PLC Bands in Al-Mg Alloys
}

Lionel Leotoing, D. Guines, Eric Robin, Jean-Benoit Le Cam

\section{- To cite this version:}

Lionel Leotoing, D. Guines, Eric Robin, Jean-Benoit Le Cam. Effects of Strain Path Changes on the Kinematics and the Intrinsic Dissipation Accompanying PLC Bands in Al-Mg Alloys. Experimental Mechanics, 2019, 59 (7), pp.963-977. 10.1007/s11340-019-00491-6 . hal-02095833

\section{HAL Id: hal-02095833 https://hal.science/hal-02095833}

Submitted on 10 Apr 2019

HAL is a multi-disciplinary open access archive for the deposit and dissemination of scientific research documents, whether they are published or not. The documents may come from teaching and research institutions in France or abroad, or from public or private research centers.
L'archive ouverte pluridisciplinaire HAL, est destinée au dépôt et à la diffusion de documents scientifiques de niveau recherche, publiés ou non, émanant des établissements d'enseignement et de recherche français ou étrangers, des laboratoires publics ou privés. 


\title{
Effects of strain path changes on the kinematics and the intrinsic dissipation accompanying PLC bands in Al-Mg alloys
}

\author{
L. Leotoing - D. Guines - E. Robin - J.-B. Le Cam
}

Received: date / Accepted: date

\begin{abstract}
Plastic instabilities, such as the Portevin-Le Chatelier (PLC) effect, reduce material ductility and induce surface roughness during sheet metal forming. The formation and propagation of PLC bands have been extensively studied by using the uniaxial tension test. However, this strain state differs from the complex strain paths encountered in most metal forming operations. In this work, the linear and non-linear strain path effects on the kinematics of PLC instabilities are investigated in an AA5086-H111 $\mathrm{Al}-\mathrm{Mg}$ alloy, at strain rates between 0.1 and $0.5 \mathrm{~s}^{-1}$. This is the first study on the spatio-temporal distribution analysis of heat produced by PLC bands during non-linear loadings. Non-linear strain paths are generated with an innovative one-step procedure, without unloading. The strain path changes are controlled by the displacements along the two perpendicular directions of a cruciform specimen loaded with a planar biaxial tensile device. For a given linear or non-linear strain path, full kinematic and thermal fields on the specimen surface were characterized by using Digital Image Correlation (DIC) and infrared thermography (IRT). Heat source fields were reconstructed from the temperature fields and the heat diffusion equation. The calorimetric response, which mainly corresponds to the intrinsic dissipation produced by the material, permits the kinematics of PLC bands to be investigated. It is shown that the strain state (uniaxial, plane strain or equibiaxial) strongly affects the formation and propagation of such plastic instabilities. For each strain path, a band typology is clearly identified. For two-step non-linear strain paths, the change in the strain state induces an instantaneous modification of the kinematics. The band kinematics is directly linked to the current strain path and the plastic deformation history does not appear to influence the typology of bands.
\end{abstract}

L. Leotoing, D. Guines

Univ Rennes, INSA Rennes, LGCGM (Laboratoire de Génie Civil et Génie Mécanique) - EA 3913 , F-35000 Rennes, France

E-mail: lionel.leotoing@insa-rennes.fr

E. Robin, J.-B. Le Cam

Univ Rennes, CNRS, IPR (Institute de Physique de Rennes) - UMR 6251, F-35000 Rennes, France

LC-DRIME, Joint Research Laboratory, Cooper Standard - Institut de Physique UMR 6251, Campus de Beaulieu, Bât. 10B, 35042 Rennes Cedex, France 
Keywords Portevin-Le Chatelier effect · aluminium alloys · strain path changes · heat source reconstruction $\cdot$ infrared thermography $\cdot$ intrinsic dissipation

\section{Introduction}

During the forming process of sheet metals, some materials exhibit plastic instabilities, such as those due to the Portevin-Le Chatelier (PLC) effect. This is the case for low carbon steels, mild steels or AlMg alloys, among others. The PLC effect is characterized by initiation and propagation of strain bands in the material [1-3], depending on forming conditions such as temperature, strain rate or strain path [4]. The propagation of bands can alter the surface finish of formed parts and decrease the ductility of materials $[5,6]$. As a consequence, characterizing the type and kinematics of such bands associated to the actual conditions of the forming process is of a paramount importance in order to validate and make the theoretical models which attempt to describe the mechanisms of band nucleation and propagation more reliable. The band motion and morphology are usually investigated under uniaxial tension. This type of loading condition is easily implementable in practice. Nevertheless, the strain path followed during an uniaxial test is not representative of the actual strain state observed during the forming process [7]. Recently, new strain paths have been studied on AA5754 in simple shear [8] and on AA5182 during hydraulic bulge deformation [9]. Likewise, Le Cam et al. [10] have identified the PLC band kinematics induced by equibiaxial tensile loading thanks to heat source maps reconstructed by the heat diffusion equation and the temperature field [11-13]. This method was previously used to study PLC effects and band kinematics in the case of uniaxial tension conditions (AA5086 and AA5052) [14,15]. For equibiaxial tensile loading, bands propagate from the center to the borders along the two loading directions, while for uniaxial tension, bands are lines oriented with an angle with respect to the loading direction. Band shape and kinematics differ from uniaxial to biaxial test, which shows that kinematics of PLC bands are directly linked to the strain state in the material.

The influence of the strain path on the mechanical behavior of sheet metals is generally studied with conventional tests (typically the Nakazima and the Marciniak tests). For these conventional tests, a punch displacement is applied and the strain path is directly linked to the specimen shape. With different shapes, quasi-linear strain paths are followed in the forming limit diagram (built from points with coordinates corresponding to in-plane principal strains), from uniaxial to equibiaxial tension. This type of test is efficient for studying linear strain paths but unsuitable for following non-linear strain paths with abrupt changes since the geometry of the specimen remains unchanged. Thus, a two-step procedure is required [16], prestrains are realized by oversized tensile tests (uniaxial or plane strain prestrains) or oversized bulge tests (biaxial prestrain). Afterwards, after unloading, conventional Marciniak or Nakazima tests can be performed on the prestrain sheets. This time-consuming method needs several experimental devices and the measurement of the strain path cannot be continuous between the two steps. Using the in-plane biaxial tensile test with a dedicated cruciform specimen to control the strain path can be an 
interesting alternative to overcome the drawbacks of conventional methods. The potential of the in-plane biaxial tensile test to study the effect of the strain path change on the forming limits has already been validated by two of the present authors $[17,18]$. It was shown that this test enables the strain path to be directly controlled by the applied speeds along the two axes, which permits the whole forming diagram under linear and non-linear strain paths to be covered. Furthermore, the change in the strain path is made without unloading and the measurement of strain is continuous. A last advantage of the outlined methodology is that complex strain paths, including several changes, can be envisaged for continuous process conditions (temperature or strain rate).

The goal of this study was to take advantage of the in-plane biaxial tensile test to fully characterize the effect of different linear and non-linear strain paths on the initiation and propagation of PLC bands in an Al-Mg alloy sheet. Kinematics and thermal fields were measured on both sides of the cruciform specimen in order to characterize the PLC band kinematics from the spatio-temporal gradients in the calorimetric response. In the first section of the paper, the experimental setup and the procedure to reconstruct the bi-dimensional heat source field are presented. In the second section, investigated strain paths are described for the different applied loading conditions. The two last sections are dedicated to the analysis of the thermal and calorimetric response of each specimen, linked to PLC band kinematics, for linear (near uniaxial, near plane strain and equibiaxial) and two non-linear (uniaxial + equibiaxial and equibiaxial + plane strain) strain paths.

\section{Experimental setup}

\subsection{Material and specimen geometry}

Al-Mg alloys have been widely used in the literature for the characterization of PLC bands [19-21]. In these alloys, interactions between solute atoms of magnesium and mobile dislocations are responsible for dynamic strain aging (DSA) and localization of dislocation activity in bands [9]. Aluminium alloy AA5086, which was annealed and slightly strain-hardened (H111), was selected in this present study. In weight percent, the main chemical components of AA5086 are: Al (93-96.3\%), Mg (3.5-4.5\%), Cr (0.05$0.25 \%), \mathrm{Mn}(0.2-0.7 \%)$ and $\mathrm{Si}(0.4 \% \max )$. The main benefits of this material are their high-strength to weight ratio, corrosion resistance, good workability and weldability characteristics. AA5086-H111 has a yield strength of $137 \mathrm{MPa}$ along the rolling direction and $121 \mathrm{MPa}$ along the transverse direction. The shape of the cruciform specimen has been optimized by two of the present authors [22] and is already described in [10]. In order to concentrate strains in the gauge region of the specimen, strain localization at the junction of the two arms is minimized by the combined effect of a radius ( $8 \mathrm{~mm})$ and of longitudinal slots $(2.2 \mathrm{~mm}$ width) that decrease the transversal stiffness of the arms. A progressive thickness reduction in the central zone is adopted to localize the crack initiation in the centre. A servohydraulic testing machine provided with four independent actuators (Figure 1) was used to test five cruciform specimens, according to different loading conditions. For each axis of the machine, imposed 
velocities can change independently in order to follow non-linear strain paths. The machine enables all the external measurement devices (load cells, camera, ...) to be triggered with a TTL signal.

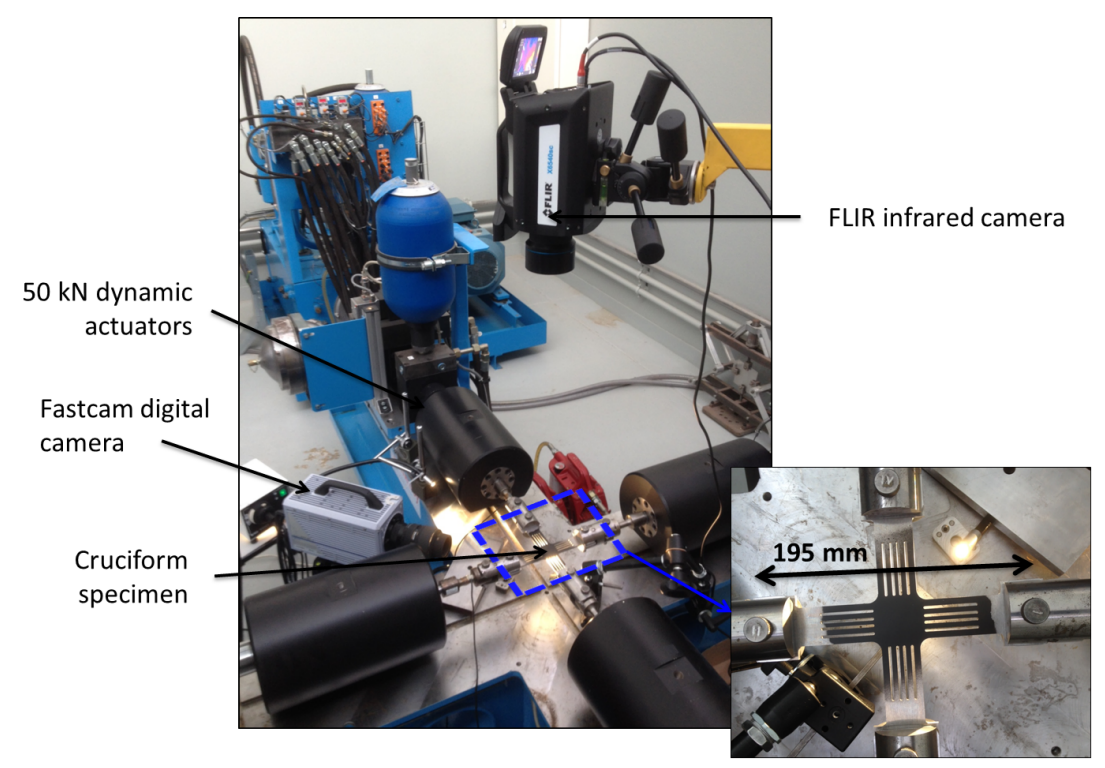

Fig. 1 Experimental set-up: images recorded with a Fastcam Ultima APX-RS digital camera and optical mirror, temperature field measurements performed using a FLIR X6540sc InSb infrared camera.

2.2 Full kinematic and thermal field measurements

Kinematics and thermal fields were measured on both sides of the cruciform specimen (Figure 1). Images of the gauge area of the cruciform specimen were recorded with a Fastcam Ultima APX-RS digital camera. Thanks to an optical mirror, the camera records images perpendicularly to the plane surface of the specimen. In this configuration, only one camera is required to measure the displacement field, as it is plane. The acquisition frequency and the spatial resolution were respectively set at 250 frames per second and $0.054 \mathrm{~mm} /$ pixel. The in-plane strain field was computed by using the Digital Image Correlation (DIC) technique. The DIC software used was CORRELA 2D. In-plane major and minor strains are calculated $(27$ points $\times 27$ points) for a square area (approximately $16 \mathrm{~mm} \times 16 \mathrm{~mm}$ ).

Temperature field measurements were performed using infrared thermography. The infrared camera used is a FLIR X6540sc infrared camera, which features a focal plane array of 640 x 512 pixels. The detectors are in the wavelength range of 1.5-5.1 $\mu \mathrm{m}$. Integration time was equal to $1000 \mu \mathrm{s}$. The noise equivalent temperature difference (NETD) was equal to $20 \mathrm{mK}$ at $25^{\circ} \mathrm{C}$. The calibration of the camera detectors was performed with a black body using a Non-Uniformity Correction procedure. The acquisition frequency was set at 250 frames per second. The frequency of the two cameras is the same and fixed with the aim of acquiring enough points for the temporal derivation of temperature in the heat diffusion equation. Temperature variation fields were obtained by subtracting the initial temperature field (before 
applying mechanical loading) from the current one. The spatial resolution, corresponding to the thermal pixel size, was equal to $0.206 \mathrm{~mm} /$ pixel. The specimen surface was sprayed with a thin, opaque and uniform black paint in order to obtain a surface emissivity close to unity.

\subsection{Heat source field reconstruction}

The heat source field is reconstructed by using the bi-dimensional formulation of the heat diffusion equation in the framework of the thermodynamics of irreversible processes. To do so, the thermodynamic process is considered as a quasi-static phenomenon and the state of any material volume element is defined by $N$ state variables. Considering the first and second principles of thermodynamics and assuming that Fourier's law is used to model heat conduction, the bi-dimensional heat diffusion equation can be written as follows:

$$
\rho C_{E, V_{k}} \dot{T}-\operatorname{div}(K \operatorname{grad} T)-r=\underbrace{d_{1}+\rho T \frac{\partial^{2} \Psi}{\partial T \partial E} \dot{E}+\rho T \frac{\partial^{2} \Psi}{\partial T \partial V_{k}} \dot{V_{k}}}_{s}
$$

where:

$-T$ is the absolute temperature,

- $E$ denotes one of the strain tensors,

$-V_{1}, V_{2}, \ldots, V_{N-2}$ are some internal variables,

- $\Psi\left(T, E, V_{k}\right)$ stands for the specific free energy potential,

$-\rho$ is the density,

- $C_{E, V_{k}}$ is the specific heat at constant $E$ and $V_{k}$,

$-r$ is the external heat source.

- $K$ is the thermal conductivity tensor,

The right-hand side of Equation (1) stands for the heat power density $s$, also referred as to the heat sources produced and absorbed by the material itself. The heat source can be split into two different contributions:

- the mechanical dissipation $d_{1}$ (or the intrinsic dissipation). This is due to some mechanical irreversibilities, such as viscosity or damage (crack growth, cavitation, etc),

- the thermomechanical couplings corresponding to the couplings between the temperature and the other state variables.

In the case of isotropic heat conduction, without any temperature gradient through the sample's thickness and without variation in the external radiations, the heat diffusion equation can be written using the measured temperature variation $\theta$ instead of temperature as follows [23]:

$$
\rho C_{E, V_{k}}\left(\dot{\theta}+\frac{\theta+T_{0}-T_{\mathrm{amb}}}{\tau}\right)-k \Delta_{2 D} \theta=s
$$


$\Delta_{2 D}$ is the two-dimensional Laplace operator in the $(x, y)$ plane. $k$ is the conductivity coefficient. $\tau$ is the time constant which characterizes the heat exchange with ambient air. This time constant can be identified from a natural return to ambient temperature.

\section{Loading conditions and mechanical response}

\subsection{Strain paths}

Figure 2 shows the evolution of strain paths at the centre of the five tested specimens (Sp1 to Sp5). Minor and major strains respectively stand for the maximum and minimum in-plane principal strains measured by the DIC method. Three of them (Sp1, Sp3 and Sp5) follow quasi-linear strain paths. For all the specimens, a constant velocity $V_{L}=1 \mathrm{~mm} / \mathrm{s}$ is imposed along the rolling direction of the sheet metal. The rolling direction coincides with one of the two perpendicular directions of the cruciform specimen. For specimen $\mathrm{Sp} 1$, the same velocity $V_{L}=1 \mathrm{~mm} / \mathrm{s}$ is defined for the transverse direction (perpendicular to the rolling direction), which leads to equibiaxial loading, as illustrated in Figure 2. For specimen Sp3, the transverse direction remains free during the test, Poisson's effect and specimen geometry lead to a strain state close to the one measured during a classical uniaxial tensile test. For specimen Sp5, a small transverse velocity $V_{T}=0.01 \mathrm{~mm} / \mathrm{s}$ is applied and as a consequence, the strain state is close to a plane strain state. For all the tests, the strain rate range is from 0.1 to $0.5 \mathrm{~s}^{-1}$.

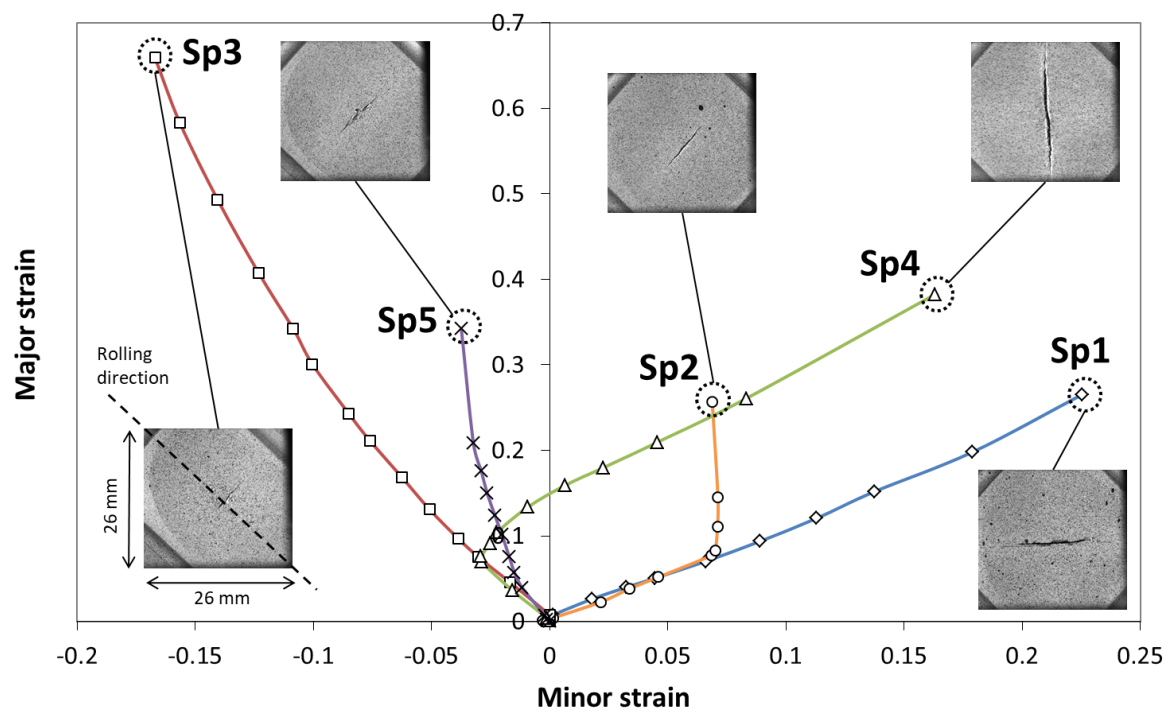

Fig. 2 Strain paths and fracture of the five specimens: Sp1 (equibiaxial), Sp2 (equibiaxial + plane strain), Sp3 (uniaxial), Sp4 (uniaxial + equibiaxial) and Sp5 (near plane strain). Rolling direction and length scale (similar for the five specimens) is specified for Sp3.

For specimen Sp2, after a first step corresponding to equibiaxial loading (like $\operatorname{Sp1}, V_{L}=V_{T}=$ $1 \mathrm{~mm} / \mathrm{s})$, an abrupt strain path change is applied $\left(V_{L}=1 \mathrm{~mm} / \mathrm{s}\right.$ and $\left.V_{T}=0.01 \mathrm{~mm} / \mathrm{s}\right)$. After the strain 
path change, the increment of minor strain is very small and only the major strain increases. The strain state after the strain path change can be related to a plane strain state since only increments of the major strain can be measured. For specimen Sp4, a prestrain step with uniaxial loading (like Sp3) is followed by an equibiaxial loading $\left(V_{L}=V_{T}=1 \mathrm{~mm} / \mathrm{s}\right)$. All the strain paths are given until fracture. Fracture orientation clearly depends on the loading path followed during the test (Figure 2). When fracture occurs under equibiaxial loading (Sp1 and Sp4), the fracture direction is oblique (45 degrees) to rolling direction. For Sp2, Sp3 and Sp5, the fracture direction is perpendicular to the rolling direction.

\subsection{Global force changes}

Force changes along rolling and transverse directions are shown in Figure 3 for the five specimens. For Sp1 and Sp2 (during the prestrain stage), the two perpendicular forces are perfectly overlapped thanks to a good synchronisation of the motion of the four actuators. For Sp2, the sudden decrease of the transverse force is linked to the strain path change. For the transverse force of Sp4, a non-zero value is measured after the prestrain stage (uniaxial tension). The near plane strain state of Sp5 leads to lower force values along the transverse direction. For the five specimens, force changes exhibit slight fluctuations. Such phenomena are typical of PLC effects and the signature (amplitude and frequency of fluctuations) is similar for all the strain paths. 


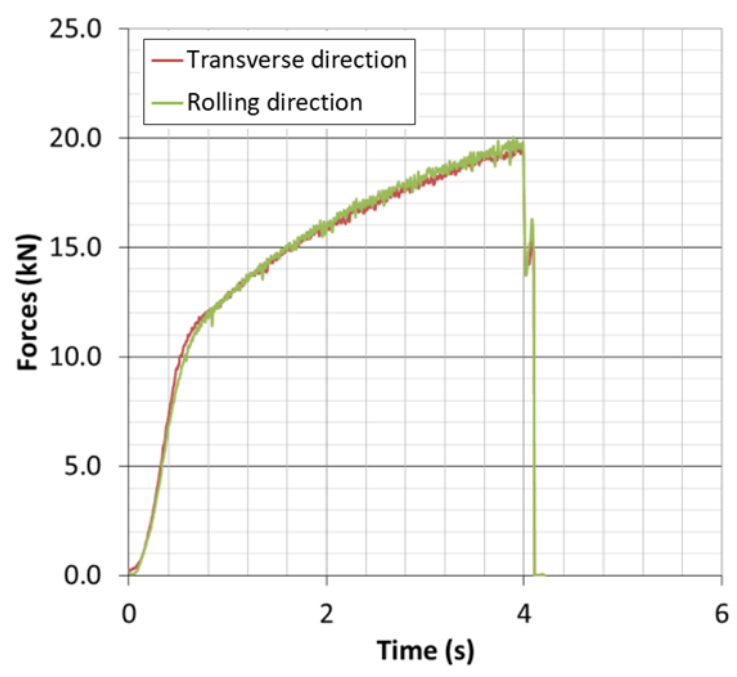

(a) $\mathrm{Sp} 1$ (equibiaxial)

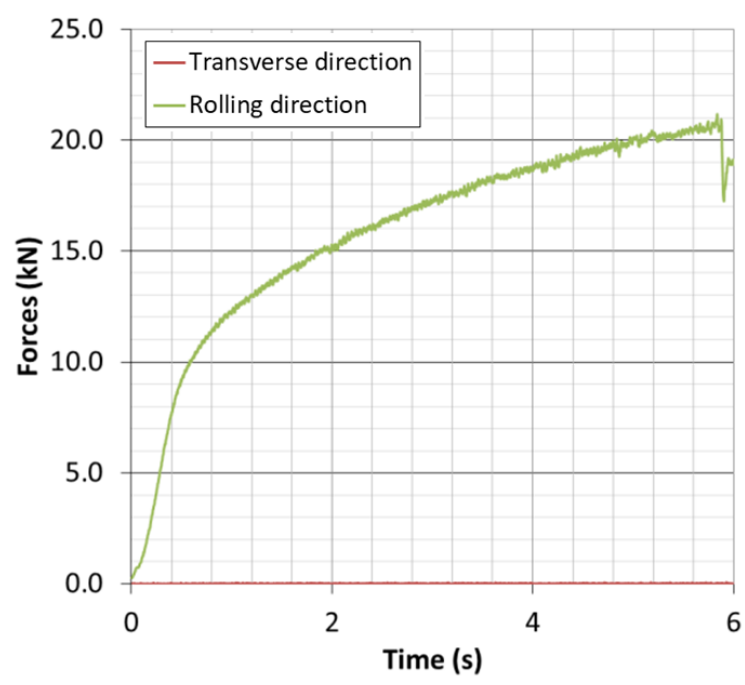

(c) Sp3 (uniaxial)

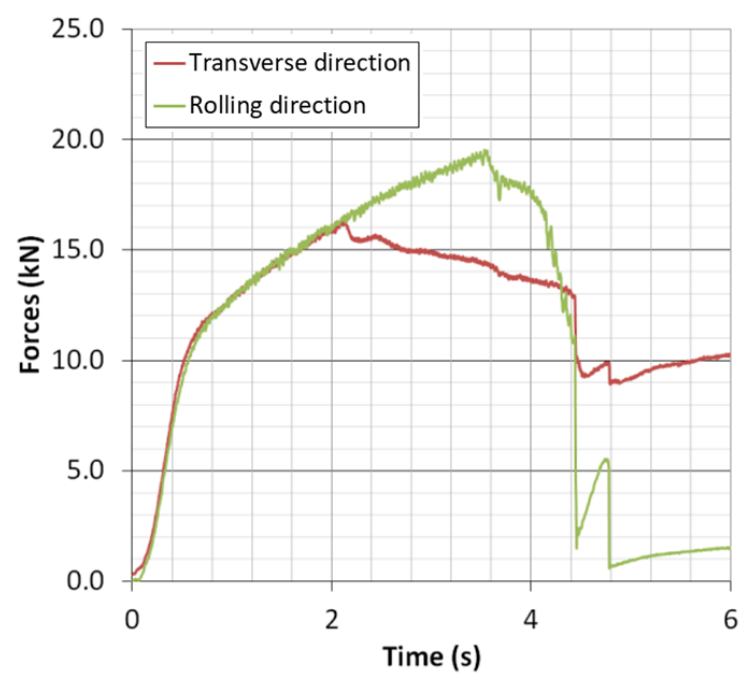

(b) Sp2 (equibiaxial + plane strain)

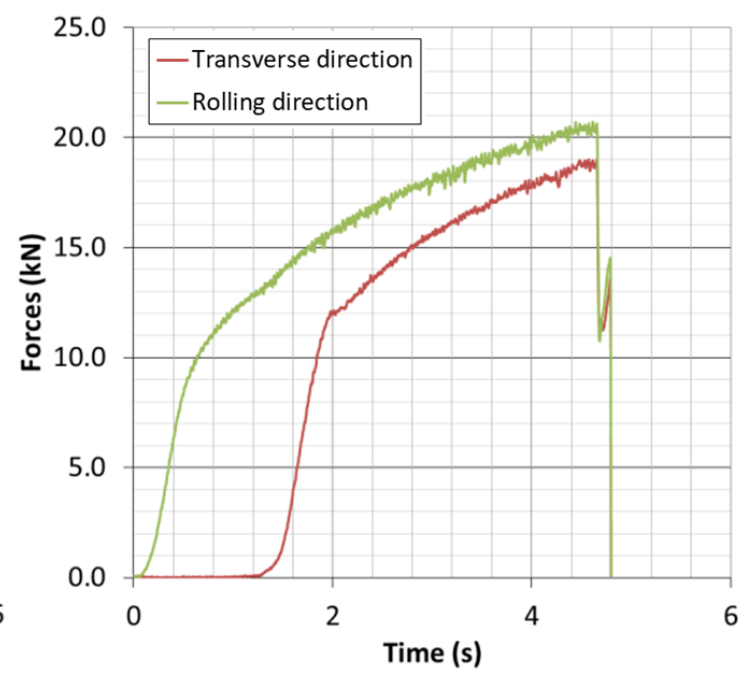

(d) $\mathrm{Sp} 4$ (uniaxial + equibiaxial)

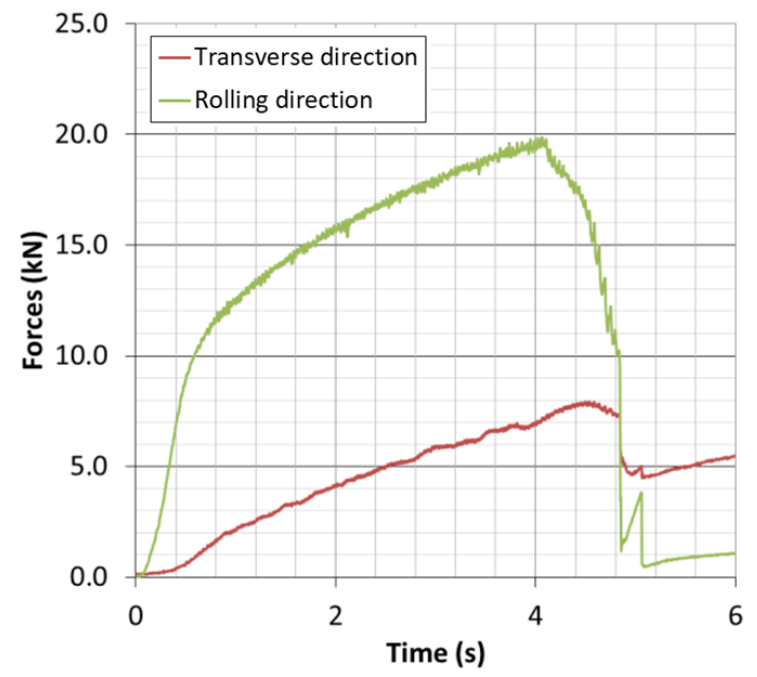

(e) Sp5 (near plane strain)

Fig. 3 Measured forces along transverse and rolling directions for the five specimens. 


\section{Effects of strain path}

In this section, the effects of the strain path on formation and propagation of PLC bands are primarily investigated. Results on specimens Sp1, Sp3 and Sp5, for which the strain path is quasi-linear during the tests, are presented and discussed.

4.1 Thermal response at the specimen center

Figure 4 shows the evolution of temperature variations versus time at the center of specimens $\mathrm{Sp} 1$ (equibiaxial stretching) and Sp3 (uniaxial tension) at the beginning of the test. Temperature is measured over a $1 \mathrm{~mm}^{2}$ surface zone at the center of the gauge region. For the two specimens, a temperature decrease is firstly observed at the beginning of the test when the response of the material is purely thermoelastic. The temperature decreases due to the elastic coupling. This is a well-known thermoelastic effect in metallic materials. During plastic deformation, the intrinsic dissipation produced is higher than the heat power density due to the thermoelastic coupling. Therefore, the temperature increases [23]. For the two specimens, the decrease is almost linear but the slope is different : the temperature decrease is higher for equibiaxial stretching than for uniaxial tension. For equibiaxial stretching, the equivalent elastic strain is twice as high as that of the uniaxial tension. Since the duration is practically the same for the two elastic stages, the largest equivalent elastic strain rate for equibiaxial stretching explains the discrepancy between the two temperature drops.

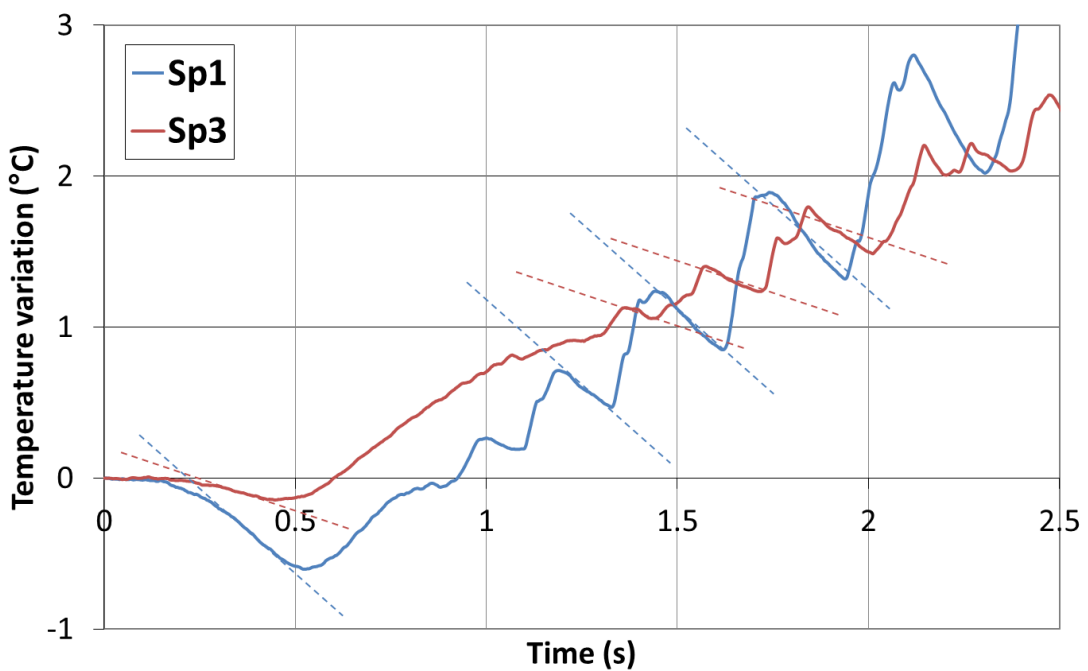

Fig. 4 Temperature variation measured in the center of specimens Sp1 (equibiaxial) and Sp3 (uniaxial). Dashed lines represent the slope of the temperature decrease at the beginning of the test, when the response of the material is purely thermoelastic. 
In the plastic domain $(t>0.5 \mathrm{~s})$, mechanical dissipation due to plasticity is produced. Formation and propagation of PLC bands are responsible for induced temperature jumps. The difference of equivalent strain rate between the two strain states (equibiaxial and uniaxial) leads to equibiaxial temperature peaks of greater amplitude in comparison to the ones in uniaxial tension. After a temperature jump, for equibiaxial stretching, it was already shown by the present authors [10] that the temperature drop was mainly due to thermoelasticity. It was demonstrated that effects of heat diffusion due to conduction and convection were of secondary importance compared to that of the thermoelastic effects. After the PLC band passage, the material deforms elastically and absorbs heat. This result is confirmed by comparing the slopes of the temperature drops for Sp1 and Sp3. For the two specimens, conduction and convection conditions were the same but the slopes of temperature drops are different for Sp1 and Sp3. For each specimen, the slope of each temperature drop is directly linked to the slope of the purely thermoelastic response measured at the beginning of the test. It should be noted that for the temperature drops observed at the highest temperature variation levels, the slopes slightly increase (in absolute value). Indeed, for the highest temperature, the heat diffusion phenomenon is increasingly significant, which accentuates the temperature decrease.

\subsection{Calorimetric response at the specimen center}

Figure 5 presents the calorimetric response obtained for specimens Sp1, Sp3 and Sp5 and the corresponding temperature variations until specimen fracture in the gauge region. Heat source field reconstruction is made according to the procedure described in section 2.3, the density and specific heat are respectively equal to $2650 \mathrm{~kg} / \mathrm{m}^{3}$ and $970 \mathrm{~J} /(\mathrm{K} . \mathrm{kg})$. Concerning the temperature variation, the maximum value is reached for specimen Sp1 (equibiaxial tension) and Sp5 (near plane strain state). There are several findings concerning the calorimetric response:

- the heat source profile strongly differs for the three linear strain paths (the value reached is lower for near plane strain state (see $\mathrm{Sp} 5)$ )

- the band occurrence frequency is slightly higher for Sp5 (approximately $4 \mathrm{~Hz}$ for Sp1 and $5.5 \mathrm{~Hz}$ for Sp5)

- between two band occurrences, the heat source is negative for all the specimens (Figure 5). The negative value is larger for equibiaxial tension (Sp1) and lower for the near plane strain state (Sp5), which explains that temperature drops between two band occurrences is lower for specimen Sp5

\subsection{PLC band kinematics}

\subsubsection{Specimen Sp1}

In Figure 6, the three heat source maps are representative of the formation and propagation of PLC bands for each jump observed with Sp1. PLC band kinematics is highly repeatable from one heat source jump 

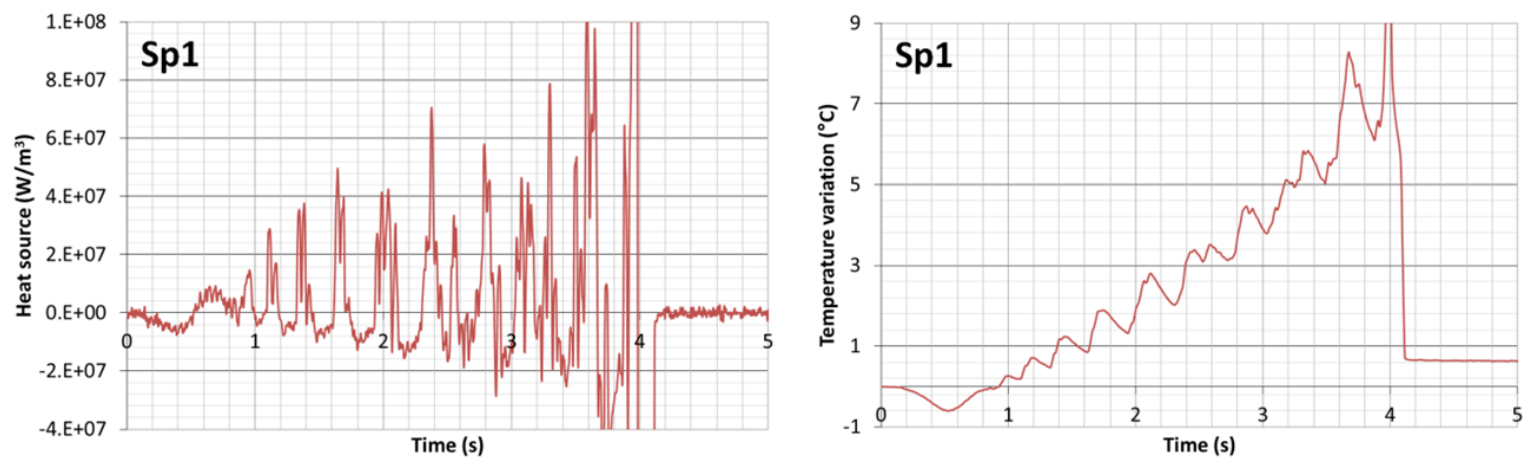

(a) Sp1 (equibiaxial)
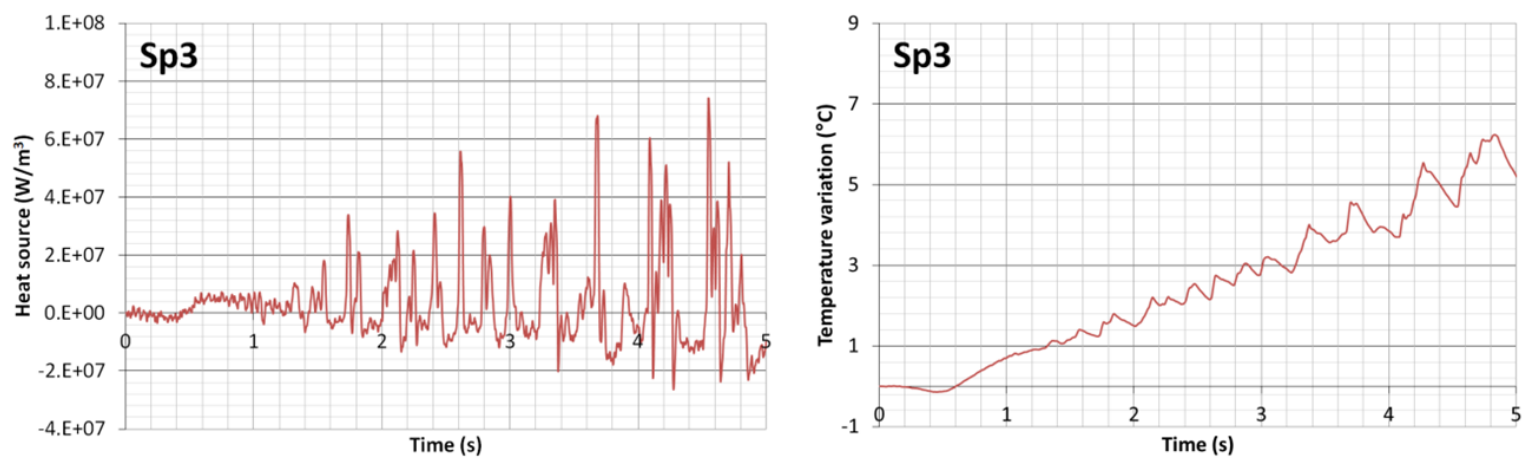

(b) Sp3 (uniaxial)
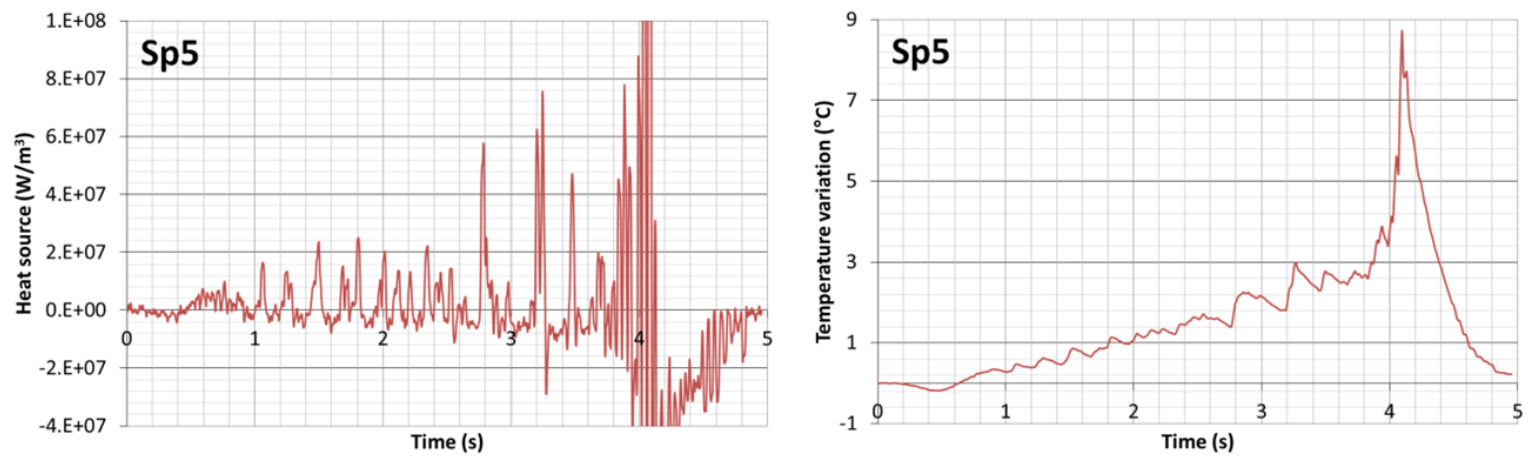

(c) Sp5 (near plane strain)

Fig. 5 Heat sources and temperature variations measured in the center of the specimens exhibited quasi linear strain paths: Sp1, Sp3 and Sp5.

to another. To discuss the calorimetric signature of PLC bands, the heat source maps are anamorphosed (the scale is variable and adjusted with maximum and minimum values for each image) in order to enhance the contrast for each image and describe the bands precisely. Due to the high strain localisation at the central point of the specimen, the PLC band shape is a cross propagating from the center to the borders, along the two loading directions. 


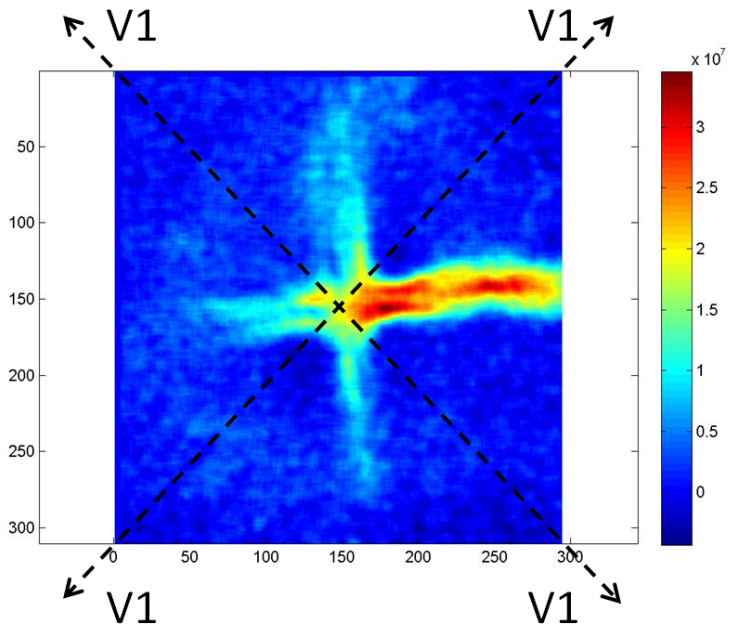

(a) $\mathrm{t}=2.336 \mathrm{~s}$

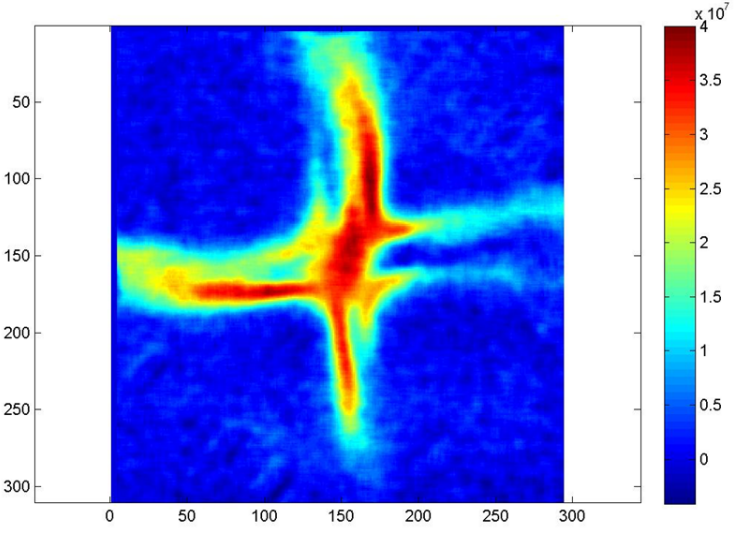

(b) $\mathrm{t}=2.368 \mathrm{~s}$

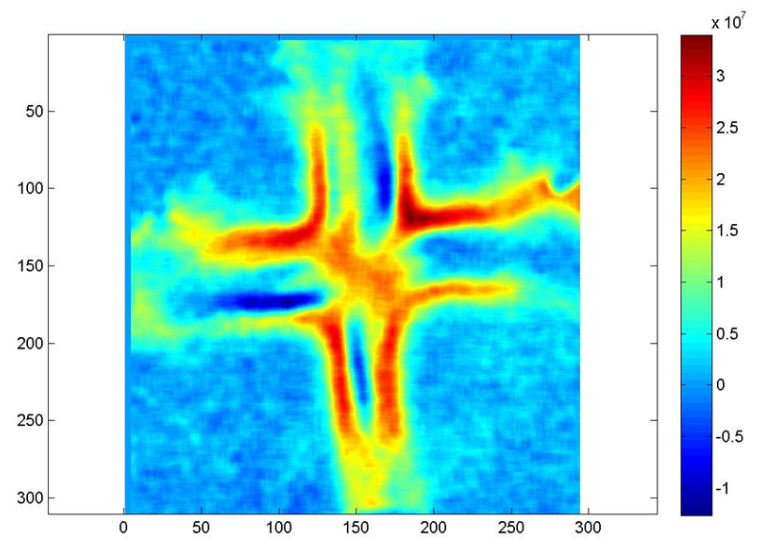

(c) $\mathrm{t}=2.4 \mathrm{~s}$

Fig. 6 Band kinematics for specimen Sp1 (equibiaxial stretching with $\mathrm{V} 1=1 \mathrm{~mm} / \mathrm{s}$ ). Bands propagate from the center to the borders, along the two loading directions (dashed lines). Heat sources are given in $W / \mathrm{m}^{3}$.

\subsubsection{Specimen Sp3}

For specimen Sp3 (uniaxial tension), PLC band kinematics is also very repeatable from one heat source jump to another. The band shape is different from the one observed in Sp1 (Figure 7). The cross form is replaced by lines oriented with a +45 or a -45 degree angle with respect to the loading direction. The orientation $(+45$ or -45$)$ alternates with heat source jumps. PLC bands duplicate and propagate from the centre of the specimen. It is noteworthy that the PLC band shape observed in the cruciform specimen loaded by uniaxial tension is very similar to the one observed in conventional uniaxial tensile tests of rectangular specimens [15,14]. Nevertheless, the value of the angle (45 degrees) is lower than the inclinations reported in the literature for Al-Mg alloys : 63 degrees for AA5052 in [15] or 57 degrees for AA5086 in [14]. When uniaxial loading is applied on a cruciform specimen and on a tensile specimen with a constant section, in-plane principal strain ratios at the center for the former (Figure 2) and in the gauge section for the latter are close but not exactly the same. For the cruciform specimen, the negative 
value of the minor strain is linked to the Poisson's effect but also to the geometry of the central zone of the cruciform shape. It is likely that the symmetry of the gauge area influences the inclination of bands and can explain the characteristic value of 45 degrees.

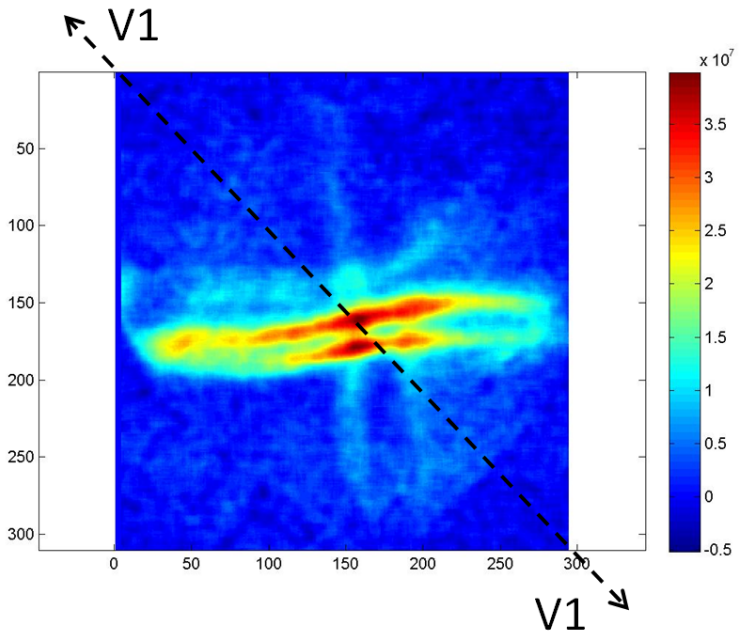

(a) $\mathrm{t}=2.42 \mathrm{~s}$

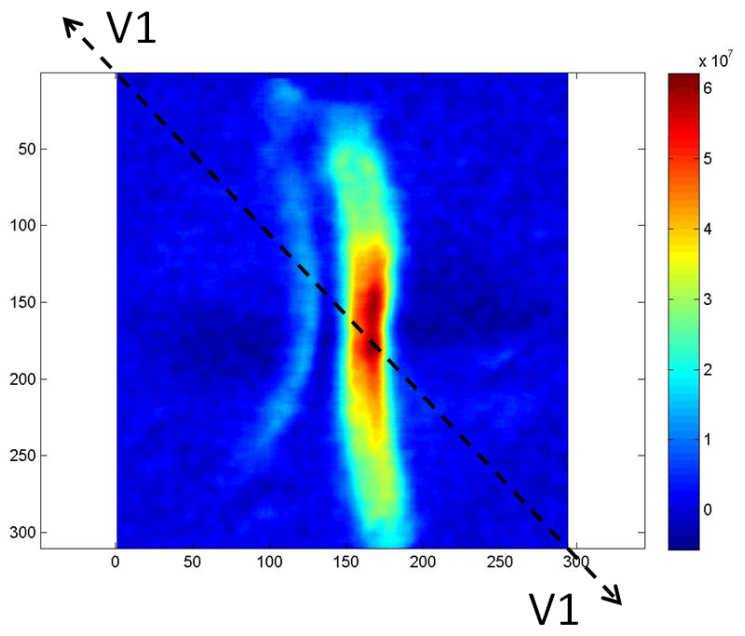

(c) $\mathrm{t}=2.624 \mathrm{~s}$

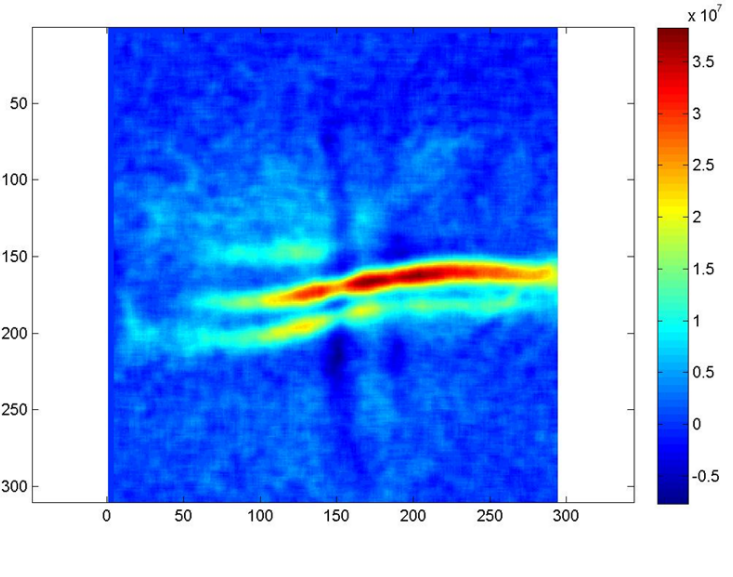

(b) $\mathrm{t}=2.452 \mathrm{~s}$

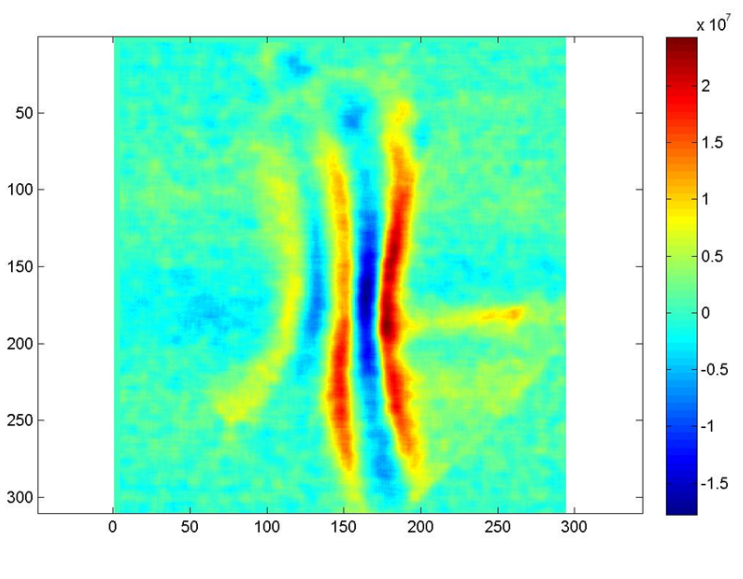

(d) $\mathrm{t}=2.648 \mathrm{~s}$

Fig. 7 Band kinematics for specimen Sp3 (uniaxial tension with $\mathrm{V} 1=1 \mathrm{~mm} / \mathrm{s}$ ). Band lines oriented with a +45 or -45 degrees angle with respect to the loading direction (dashed line). Heat sources are given in $W / m^{3}$.

\subsubsection{Specimen Sp5}

Figure 8 shows the PLC band kinematics for Sp5, near the plane strain state. The band morphology for Sp3 and Sp5 is comparable but the orientation is very different. PLC bands duplicate and propagate from the centre of the specimen, along the direction defined by the actuators moving at the highest speed. As observed in Figure 8, bands are mainly oriented perpendicular to this direction. 


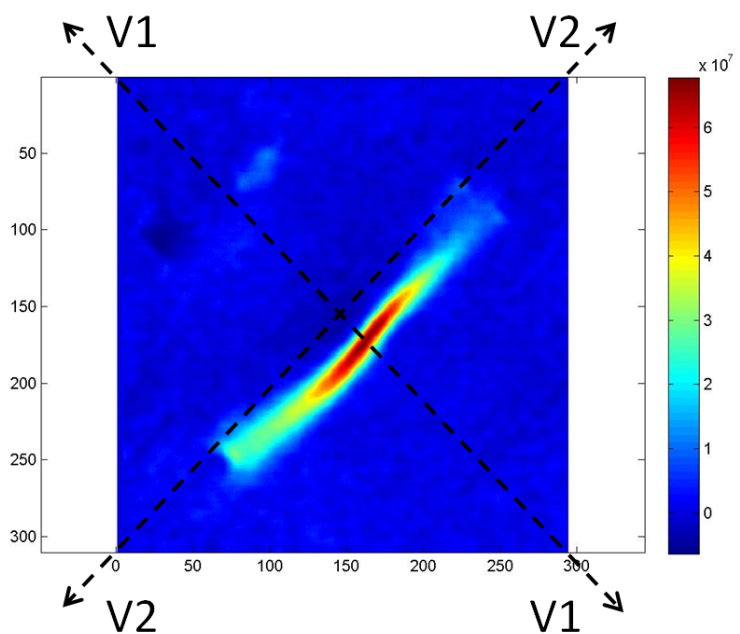

(a) $t=3.196 \mathrm{~s}$

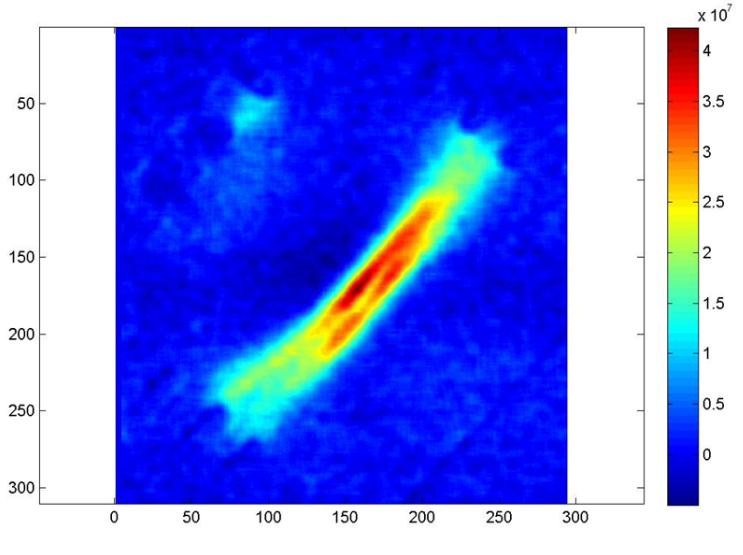

(b) $\mathrm{t}=3.216 \mathrm{~s}$

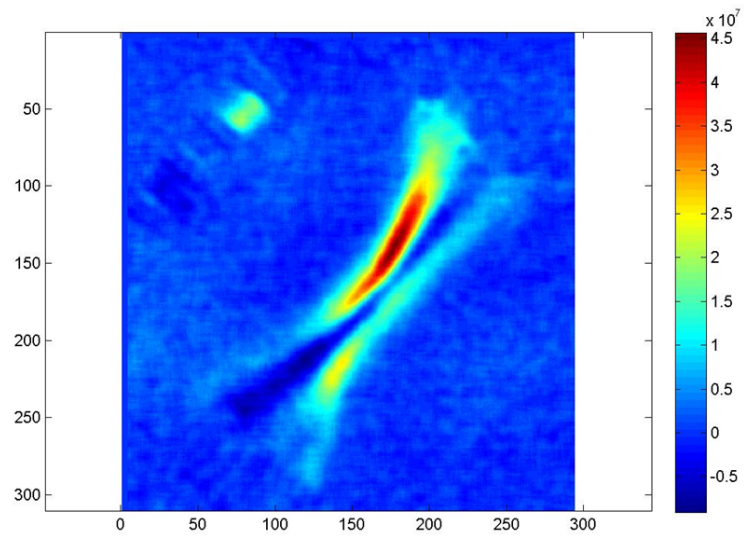

(c) $\mathrm{t}=3.236 \mathrm{~s}$

Fig. 8 Band kinematics for specimen Sp5 (near plane strain state, V1=1 mm/s and V2=0.01 mm/s). Bands mainly oriented perpendicular to the loading direction of highest velocity (V1). Heat sources are given in $W / m^{3}$.

\subsubsection{Typology of band kinematics}

The PLC band kinematics observed with the three previous specimens and corresponding to three characteristic linear strain paths are summarized in Figure 9 : a cross form for equibiaxial loading and lines with different angles for the two other loadings. In order to facilitate the characterization of effects of non-linear strain paths on PLC band kinematics in the following section, we propose to introduce a band kinematics typology based on the morphology and orientation of bands:

- Mode X : cross shape for equibiaxial loading

- Mode U : bands oriented with a given angle with respect to the loading direction (uniaxial tension)

- Mode P : bands perpendicular to the main loading direction (plane strain state) 


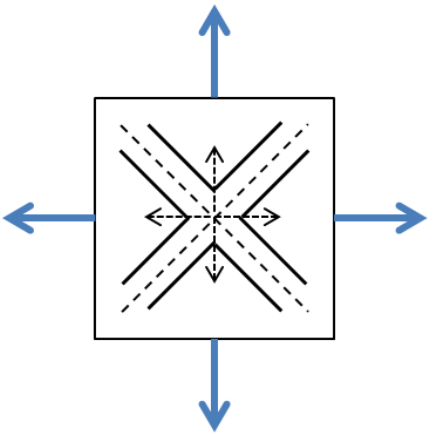

Equibiaxial (mode $\mathrm{X}$ )

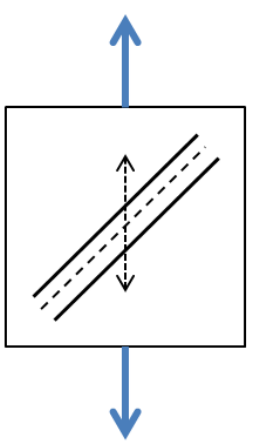

Uniaxial (mode U)

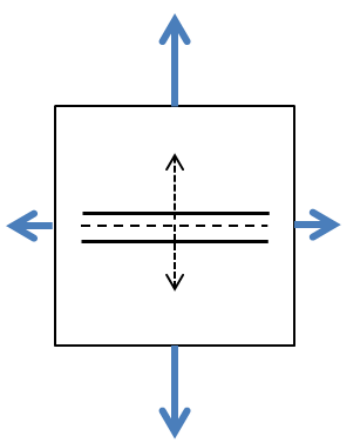

Plane strain (mode P)

$\rightarrow$ Loading direction

$------\rightarrow$ Direction of band propagation

Fig. 9 Illustration of the observed band modes : equibiaxial (mode X), uniaxial (mode U) and plane strain (mode P).

\section{Effect of strain path changes}

5.1 Thermal response at the specimen center

Figure 10 gives the temperature variations at the center of the cruciform specimen versus time for Sp1 and Sp2. For the two specimens, an equibiaxial loading is applied at the beginning of the test (up to $2.264 \mathrm{~s})$. A very good reproducibility is observed for this first step of loading with the same temperature jumps of PLC bands formation and propagation. This clearly demonstrates that onset of PLC bands is not a random phenomenon. The change in the strain path $(\mathrm{t}=2.264 \mathrm{~s})$ induces an abrupt divergence in the temperature evolution at the center of the specimen and shows the strong influence of the strain path change on the thermal response.

The same phenomenon is observed for Sp3 and Sp4 (Figure 11). When equibiaxial loading is applied for Sp4 $(\mathrm{t}=1.42 \mathrm{~s})$, after a first step in uniaxial tension, a strong decrease of temperature is observed and temperature jumps return $(\mathrm{t}=2.2 \mathrm{~s})$ after an elapsed time without PLC bands. As already mentioned and explained, temperature jumps for equibiaxial loading (Sp1 and Sp2 in Figure 10 before $2.3 \mathrm{~s}, \mathrm{Sp} 4$ in Figure 11 after $2.2 \mathrm{~s}$ ) are higher than for uniaxial loading (Sp3 in Figure 11). The frequency of the jumps is also different for the two types of loading.

\subsection{Calorimetric response}

The change in the strain path has been identified by points A (Sp2) and B (Sp4) in Figures 12 and 13, respectively. At these points, the calorimetric response is singular: no PLC band occurs and just after the strain path change, the material seems to deform elastically since the heat source is negative and no heat source jump is observed. 


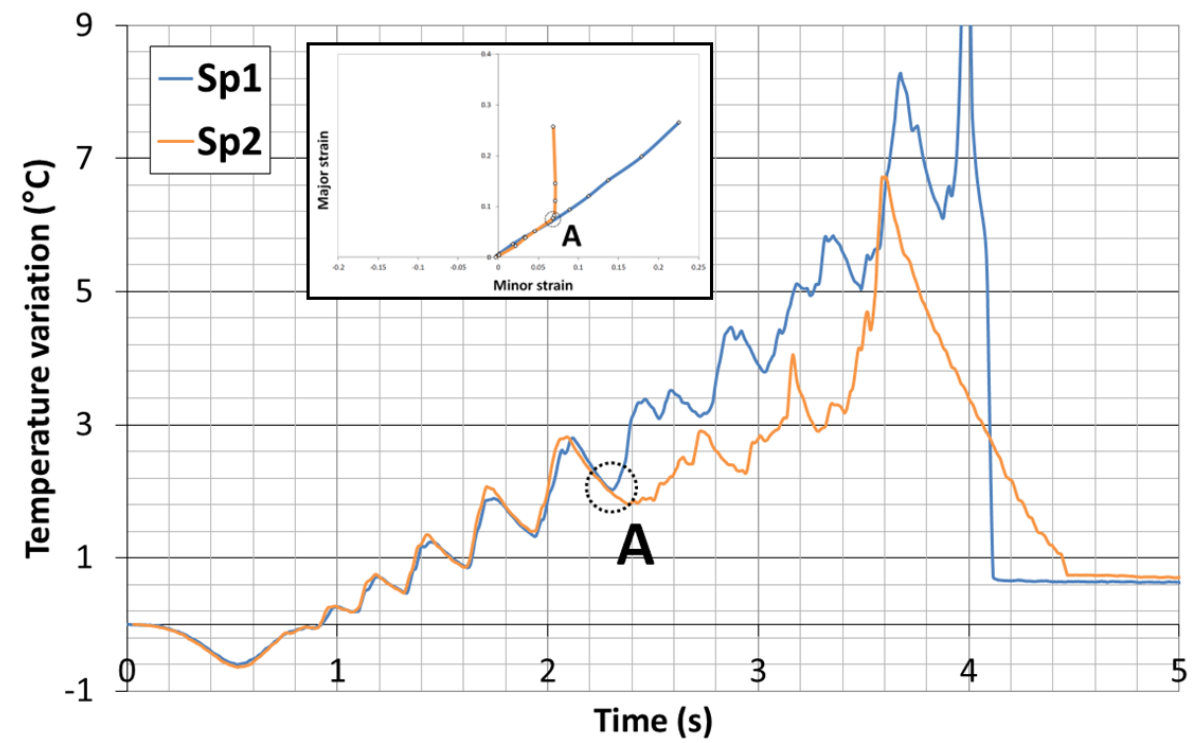

Fig. 10 Temperature variation in the center for Sp1 (equibiaxial strain state) and Sp2 (from equibiaxial to plane strain state). Point A ( $t=2.264 \mathrm{~s}$ ) indicates the change in strain path for specimen Sp2 (evolution of strain paths for $\mathrm{Sp} 1$ and Sp2 is recalled in the figure).

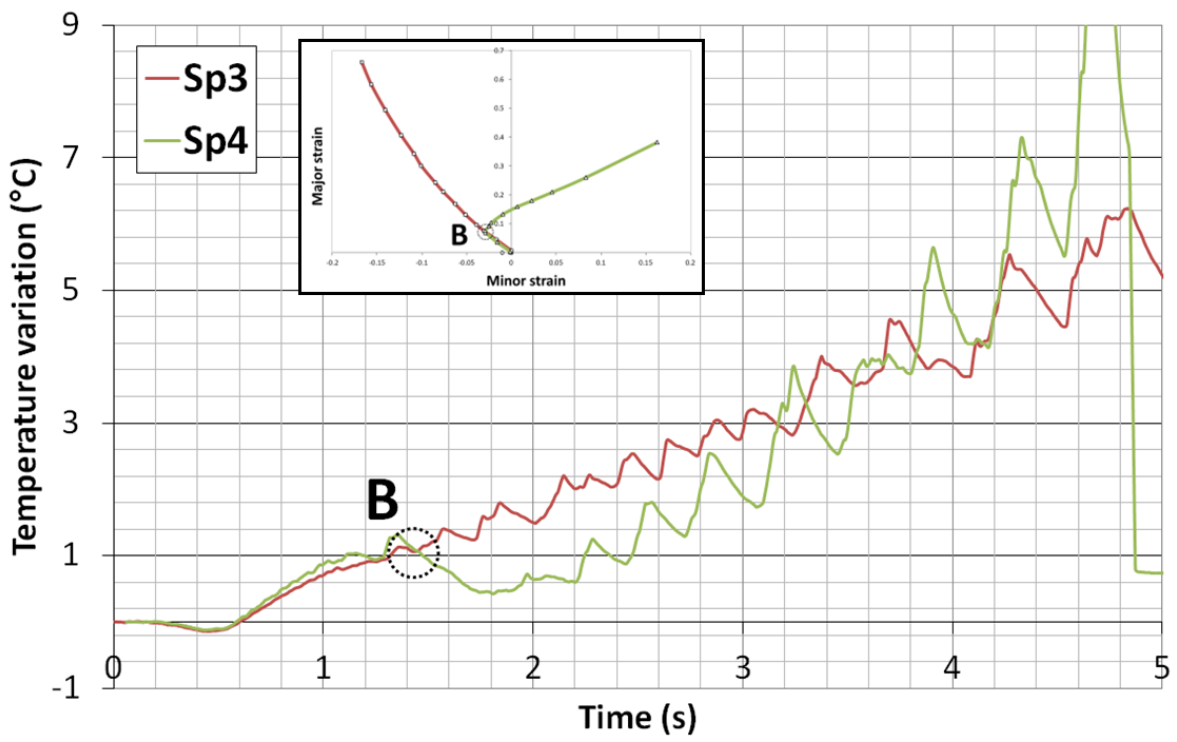

Fig. 11 Temperature variation in the center for Sp3 (near uniaxial strain state) and Sp4 (from uniaxial to equibiaxial state). Point B ( $\mathrm{t}=1.42 \mathrm{~s})$ indicates the change in strain path for specimen Sp4 (evolution of strain paths for Sp3 and $\mathrm{Sp} 4$ is recalled in the figure).

\subsection{PLC band kinematics}

Figures 14 and 15 illustrate the band kinematics and more especially the change in the band kinematics, from Mode $\mathrm{X}$ to Mode $\mathrm{P}$ for $\mathrm{Sp} 2$ and from Mode $\mathrm{U}$ to Mode $\mathrm{X}$ for Sp4. The band kinematics is directly linked to the type of loading and not to the strain state in the material in the sense that plastic 


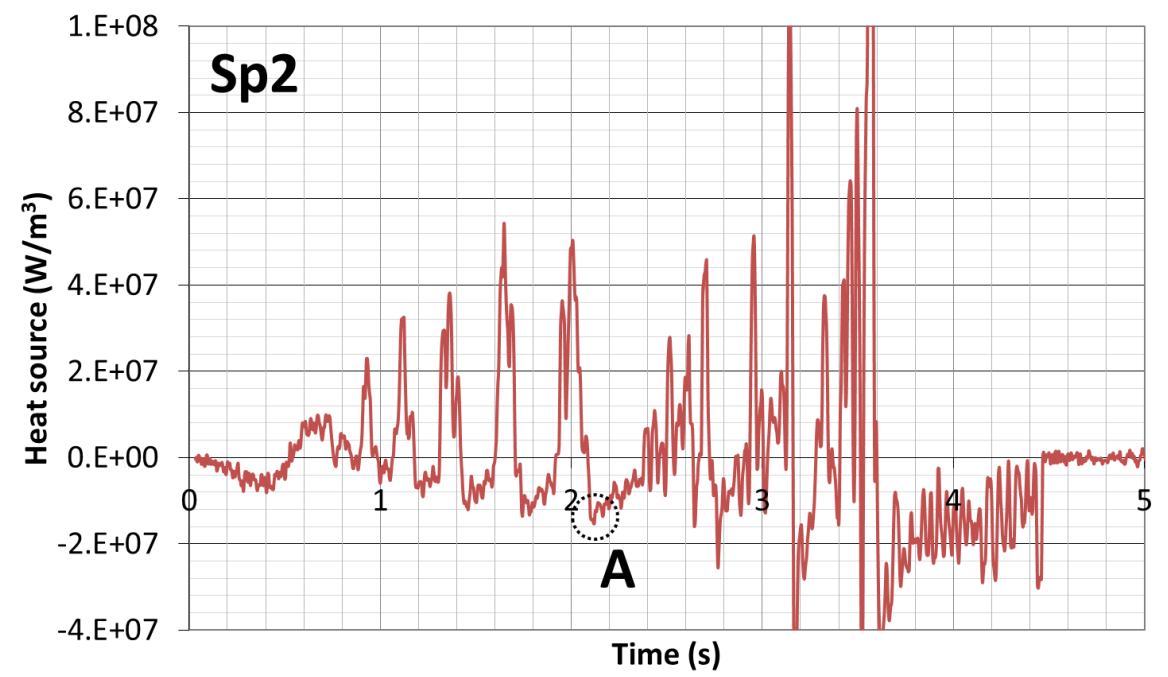

Fig. 12 Evolution of heat sources calculated in the center of specimen Sp2 (from equibiaxial to plane strain state) during the test. Point A $(\mathrm{t}=2.264 \mathrm{~s})$ indicates the change in strain path.

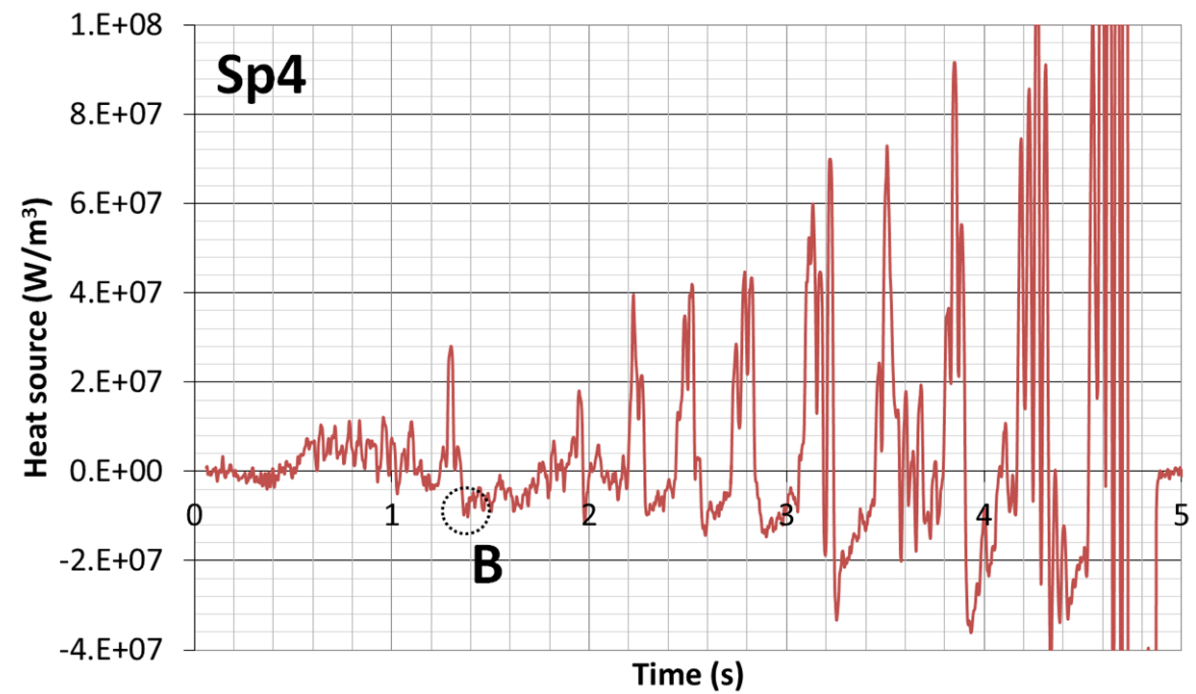

Fig. 13 Evolution of heat sources calculated in the center of specimen Sp4 (from uniaxial to equibiaxial state) during the test. Point B $(\mathrm{t}=1.42 \mathrm{~s})$ indicates the change in strain path.

deformation history does not appear to influence band kinematics. In other words, the band kinematics can be deduced from the current strain path.

The same final strain state can be reached by different strain paths with different band kinematics, see for instance the intersection between the Sp2 and Sp4 strain paths in Figure 2. Further investigations are required in order to show if an optimized strain path can minimize defects induced by plastic instabilities at the surface finish. 

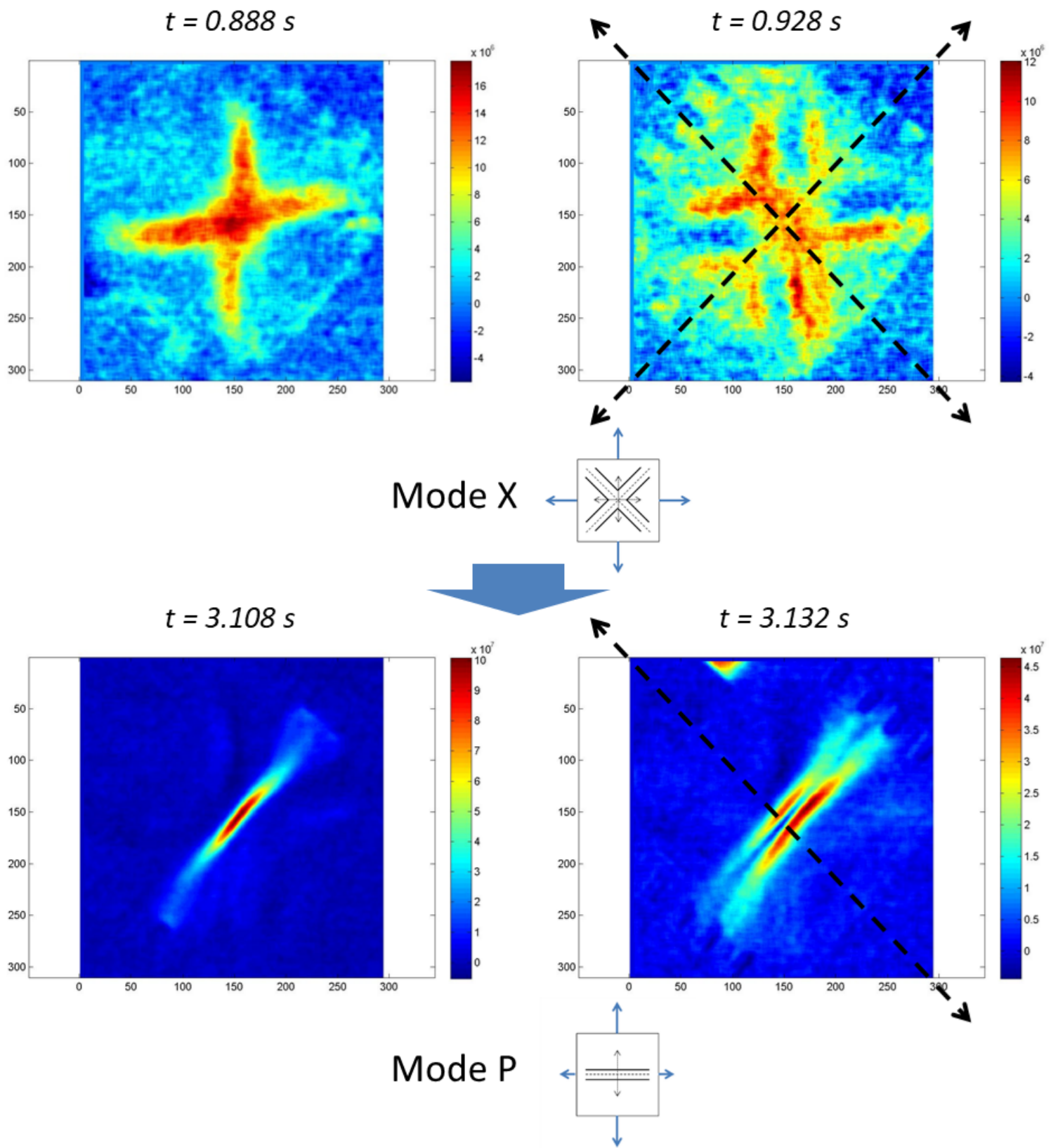

Fig. 14 Band kinematics for specimen Sp2 (from equibiaxial to plane strain state). Typology of band kinematics (mode $\mathrm{X}$ and mode $\mathrm{P}$ ) introduced previously are used to qualify the different modes. Black dashed lines indicate the directions of propagation of bands. 

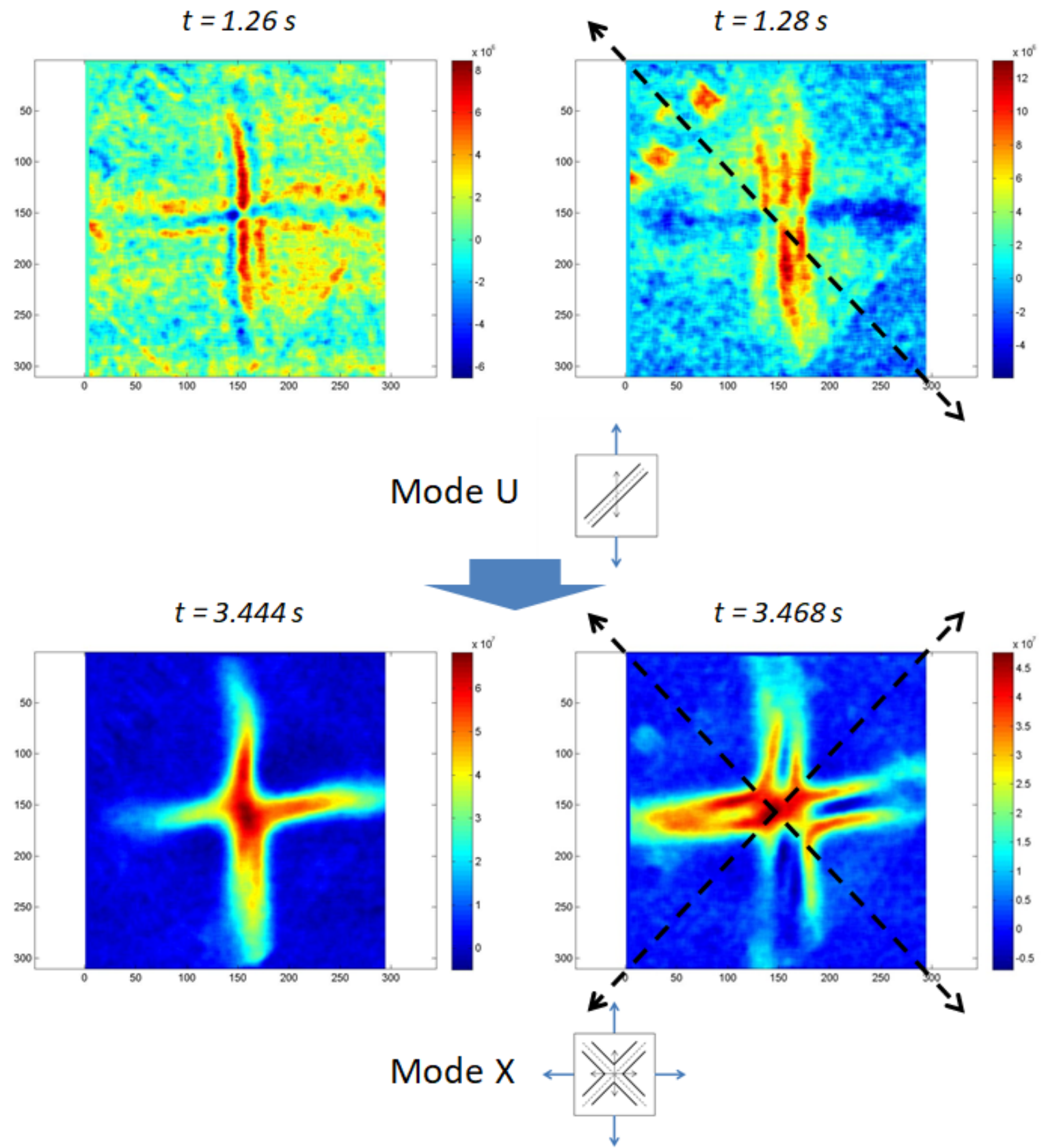

Fig. 15 Band kinematics for specimen Sp4 (from uniaxial to equibiaxial state). Typology of band kinematics (mode $\mathrm{U}$ and mode X) introduced previously are used to qualify the different modes. Black dashed lines indicate the directions of propagation of bands. 


\section{Conclusions}

In the present work, different linear and non-linear strain paths, without unloading, were applied in the central zone of cruciform specimens. The heat source map enables us to visualize spatio-temporal gradients in the calorific response of the material and to investigate the morphology and kinematics of PLC bands induced by the different loadings. The key findings are as follows :

- For three linear strain paths (uniaxial loading, equibiaxial loading and plane strain condition), the heat sources exhibit jumps directly linked to the passage of PLC bands at the specimen centre. The strain state in the material strongly affects the morphology of PLC bands. For each strain path, a PLC band typology is clearly identified (modes $\mathrm{X}, \mathrm{U}$ and $\mathrm{P}$ ).

- After a strain path change during a loading, from equibiaxial to plane strain or from uniaxial to equibiaxial, the material deforms elastically since the heat source is negative and no heat source jump is observed. After this stage, the occurrence of plastic deformation generates propagation of new PLC bands.

- It must be emphasized that the plastic deformation history does not influence the typology of PLC bands. The band kinematics of the current strain path is similar to that observed in the monotonic test with the same strain path.

Acknowledgements The authors thank the National Center for Scientific Research (MRCT-CNRS and MI-CNRS) and Rennes Metropole for supporting this work financially.

\section{References}

1. Y. Estrin, L.P. Kubin, and E.C. Aifantis. Introductory remarks to the viewpoint set on propagative plastic instabilities. Scripta Metallurgica et Materialia, 29(9):1147 - 1150, 1993.

2. M. Zaiser and P. Hahner. Oscillatory modes of plastic deformation: Theoretical concepts. Physica Status Solidi (b), 199(2):267-330, 1997.

3. E. Rizzi and P. Hahner. On the portevin-le chatelier effect: theoretical modeling and numerical results. International Journal of Plasticity, 20(1):121 - 165, 2004.

4. H. Laurent, J. Coër, P.Y. Manach, M.C. Oliveira, and L.F. Menezes. Experimental and numerical studies on the warm deep drawing of an Al-Mg alloy. International Journal of Mechanical Sciences, 93:59 - 72, 2015.

5. J.M. Robinson. Aspects of serrated flow in aluminium alloys. PhD thesis, Faculty of Engineering of the University of Cape Town, 1992.

6. A. Yilmaz. The portevin-le chatelier effect: a review of experimental findings. Science and Technology of Advanced Materials, 12, 2011.

7. D. Banabic. Sheet Metal Forming Processes - Constitutive modelling and numerical simulation. Springer, 2010.

8. J. Coër, P.Y. Manach, H. Laurent, M.C. Oliveira, and L.F. Menezes. Piobert-Lüders plateau and Portevin-Le Chatelier effect in an Al-Mg alloy in simple shear. Mechanics Research Communications, 48:1 - 7, 2013.

9. J. Min, L.G. Hector, J.E. Carsley, T.B. Stoughton, B.E. Carlson, and J. Lin. Spatio-temporal characteristics of plastic instability in AA5182-O during biaxial deformation. Materials and Design, 83:786 - 794, 2015. 
10. J.-B. Le Cam, E. Robin, L. Leotoing, and D. Guines. Calorimetric analysis of portevin-le chatelier bands under equibiaxial loading conditions in Al-Mg alloys: Kinematics and mechanical dissipation. Mechanics of Materials, 105:80-88, 2017 .

11. A. Chrysochoos and H. Louche. Thermal and dissipative effects accompanying luders band propagation. Mat Sci Eng A-struct, 307:15-22, 2001.

12. B. Wattrisse, A. Chrysochoos, J.-M. Muracciole, and M. Némoz-Gaillard. Analysis of strain localization during tensile tests by digital image correlation. Experimental Mechanics, 41:29-39, 2001.

13. A. Chrysochoos, V. Huon, F. Jourdan, J.-M. Muracciole, R. Peyroux, and B. Wattrisse. Use of full-field digital image correlation and infrared thermography measurements for the thermomechanical analysis of material behaviour. Strain, 46:117-130, 2010.

14. H. Louche, P. Vacher, and R. Arrieux. Thermal observations associated with the portevin-le chatelier effect in an al-mg alloy. Materials Science and Engineering: A, 404:188 - 196, 2005.

15. D. Delpueyo, X. Balandraud, and M. Grediac. Calorimetric signature of the Portevin-Le Chatelier effect in an aluminum alloy from infrared thermography measurements and heat source reconstruction. Materials Science and Engineering: A, 651:135 - 145, 2016.

16. W. Volk, H. Hoffmann, J. Suh, and J. Kim. Failure prediction for nonlinear strain paths in sheet metal forming. CIRP Annals - Manufacturing Technology, 61:259-262, 2012.

17. L. Leotoing and D. Guines. Investigations of the effect of strain path changes on forming limit curves using an in-plane biaxial tensile test. International Journal of Mechanical Sciences, 99:21-28, 2015.

18. X. Song, L. Leotoing, D. Guines, and E. Ragneau. Investigation of the forming limit strains at fracture of AA5086 sheets using an in-plane biaxial tensile test. Engineering Fracture Mechanics, 163:130-140, 2016.

19. J. Balik and P. Lukac. Portevin-le chatelier instabilities in al-3 mg conditioned by strain rate and strain. Acta Metallurgica et Materialia, 41(5):1447 - 1454, 1993.

20. A. Korbel and H. Dybiec. The problem of the negative strain-rate sensitivity of metals under the portevin-le chatelier deformation conditions. Acta Metallurgica, 29(1):89 - 93, 1981.

21. M. Li and DJ Lege. Serrated flow and surface markings in aluminum alloys. J. Eng. Mater. Technol., 120:48-56, 1998.

22. I. Zidane, D. Guines, L. Leotoing, and E. Ragneau. Development of an in-plane biaxial test for forming limit curve (flc) characterization of metallic sheets. Measurement Science and Technology, 21(5):055701, 2010.

23. A. Chrysochoos and H. Louche. An infrared image processing to analyse the calorific effects accompanying strain localisation. Int J Eng Sci, 38:1759-1788, 2000. 